\title{
"O primeiro sofrimento que os imigrantes passam é de não entender nada da língua": em busca do português brasileiro como língua de acolhimento para imigrantes
}

\section{"The first suffering that immigrants go through is not understanding the language at all": looking forward to Brazilian Portuguese as a host language for immigrants}

\author{
Marina Alves Cavinato 1 \\ Eduarda Portella Gallina² \\ Minéia Frezza ${ }^{3}$
}

\begin{abstract}
Resumo
Atualmente, o Brasil insere-se no cenário internacional das migrações de crise como destino de milhares de imigrantes. Assim, torna-se necessário implantar políticas de acolhimento à essa população. Nesse sentido, o ensino de Português como Língua de Acolhimento (PLAc) constitui uma das principais formas de promoção da integração de imigrantes na sociedade brasileira. No entanto, os materiais didáticos de PLAc disponíveis são limitados em termos de interações naturalísticas e dos contextos comunicativos relevantes às demandas dos imigrantes (MIRANDA; LOPEZ, 2019; PERNA; ANDRIGHETTI, 2019). Como parte de um projeto de pesquisa desenvolvido no Instituto Federal do Rio Grande do Sul - Campus Farroupilha denominado "O português brasileiro falado na Serra Gaúcha como língua de acolhimento para imigrantes", o qual pretende elaborar materiais didáticos de PLAc que atendam às necessidades dos imigrantes, o presente estudo visa analisar entrevistas com imigrantes residentes no Rio Grande do Sul com o foco em elencar as instituições e os contextos interacionais mais relevantes para eles. Além da análise dos dados coletados, que foi feita através da metodologia da Análise de Conteúdo, realiza-se uma breve discussão sobre três temas mencionados pelos participantes da pesquisa: a inserção dos imigrantes no mercado de trabalho formal brasileiro, a importância da mediação linguística e alternativas de Políticas de Acolhimento. A partir dos dados coletados, será possível realizar gravações de interações naturalísticas nos locais elencados pelos participantes, as quais darão subsídio à produção de materiais didáticos de PLAc adequados às suas demandas.
\end{abstract}

Palavras-chave: Imigrações de crise. Português como Língua de Acolhimento. Políticas de Acolhimento e Integração de Imigrantes e Refugiados.

\begin{abstract}
Currently, Brazil is part of the international crisis migrations as a destination for thousands of immigrants. Thus, it becomes necessary to implement welcoming policies for this population. In this sense, teaching Portuguese as a Host Language (PLAc) is one of the main ways to promote the integration of immigrants into Brazilian society. However, PLAc teaching materials available are limited in terms of naturalistic interactions and communicative contexts relevant to immigrants' demands (MIRANDA; LOPEZ, 2019; PERNA; ANDRIGHETTI, 2019). As part of a research project developed at the Federal Institute of Instituto Federal do Rio Grande do Sul - Campus Farroupilha called "O português brasileiro falado na Serra Gaúcha como língua de acolhimento para imigrantes", which aims to develop PLAc teaching materials that meet the needs of immigrants, this study aims to analyze interviews held with immigrants who currently live in Rio Grande do Sul with a focus on listing the most relevant institutions and interactional contexts for them. In addition to the analysis of the collected data, which was carried out using the Content Analysis methodology, there is a brief discussion on three themes mentioned by the research participants: the insertion of immigrants in the Brazilian formal labor market, the importance of linguistic mediation and
\end{abstract}

1 Estudante do Ensino Médio Integrado ao Técnico em Administração. Instituto Federal de Educação, Ciência e Tecnologia do Rio Grande do Sul, Farroupilha, RS, Brasil. Orcid: https://orcid.org/0000-0002-6399-8707. E-mail: marinacavinato@gmail.com.

2 Estudante do Ensino Médio Integrado ao Técnico em Administração. Instituto Federal de Educação, Ciência e Tecnologia do Rio Grande do Sul, Farroupilha, RS, Brasil. Orcid: https://orcid.org/0000-0001-8045-6283 E-mail: gallinaeduarda@gmail.com.

3 Doutora em Linguística Aplicada. Instituto Federal de Educação, Ciência e Tecnologia do Rio Grande do Sul, Farroupilha, RS, Brasil. Orcid: https://orcid.org/0000-0002-4480-898X. E-mail: mineia.frezza@farroupilha.ifrs.edu.br. 
alternative Welcoming Policies. Based on the collected data, it will be possible to record naturalistic interactions in the places listed by the participants, which will subsidize the production of PLAc teaching materials suited to their demands.

Keywords: Crisis immigrations. Portuguese as a Host Language. Welcoming and Integration Policies for Immigrants and Refugees.

\section{Introdução}

Atualmente, o Brasil tornou-se o destino de diversos fluxos migratórios, inserindo-se, dessa forma, no cenário internacional de migrações. Devido a inúmeros fatores, refugiados e imigrantes de múltiplas nacionalidades deslocam-se em busca de melhores condições de vida. Neste texto, adotamos o conceito de "migração de crise", apresentado por Clochard (2007 apud CAMARGO, 2018, p. 59), que diz respeito às " [...] migrações que são forçadas por problemas econômicos, políticos, civis, religiosos e humanitários". Entende-se que o escopo teórico-conceitual da migração de crise abrange, tal qual apresentado por Baeninger e Peres (2017, p. 122), distintas classificações, como "[...] imigrantes com a condição jurídica de refugiado, imigrantes solicitantes de refúgio, imigrantes com 'refúgio humanitário', crise humanitária e imigrantes refugiados ambientais".

Entre os anos de 2011 e 2019, conforme o relatório do OBMigra (CAVALCANTI et al., 2020), considerando os amparos legais, foram registrados 1.085.673 imigrantes no Brasil. Já uma pesquisa realizada pelo IBGE (2019) indica que, entre 2010 e 2018, o Brasil registrou 466.000 imigrantes, bem como 116.400 pedidos de refúgio.

Apesar do intenso deslocamento de migrantes de crise tendo como destino o território brasileiro, nota-se a falta de políticas públicas e de acolhimento para essa população. Essa informação é confirmada por uma pesquisa feita pelo IBGE (2019), que apontou que somente 5,5\% dos municípios brasileiros que recebem imigrantes possuem algum tipo de serviço de acolhimento voltado à integração dessas pessoas, tais como cooperação entre o município e os demais entes da federação, relação entre a prefeitura e a associação ou coletivo de imigrantes, oferta de curso de português, atendimento multilíngue nos serviços públicos, abrigo para acolhimento de imigrantes, Centros de Referência e Apoio a imigrantes e formação e capacitação continuada interdisciplinar para o atendimento dessa população.

Uma das formas mais efetivas de promover a integração dos imigrantes na sociedade brasileira é o ensino de Português como Língua de Acolhimento (PLAc). Oliveira e Silva (2017, p. 147) defendem que "conhecer a língua oficial do país acolhedor não só é um fator fundamental no processo de inclusão e empoderamento social dos imigrantes, como é também um direito deles". Nesse sentido, desenvolveuse, no Instituto Federal de Educação, Ciência e Tecnologia do Rio Grande do Sul (IFRS) - Campus Bento Gonçalves, o Projeto de Extensão "Língua Portuguesa para imigrantes e refugiados", o qual oferta um 
curso de PLAc a imigrantes. O objetivo do referido curso é, tal qual apresentado por Balzan e Kanitz (2020, p. 277),

[...] promover um aprendizado da língua portuguesa que permita aos sujeitos comunicar-se em situações cotidianas de interação social como: apresentar-se, pedir informações, locomover-se pela cidade, fazer compras, procurar emprego, providenciar documentação, acessar os serviços públicos de assistência social, saúde e educação. (BALZAN; KANITZ, 2020, p. 277)

A despeito disso, a literatura relacionada a PLAc aponta a dificuldade em encontrar materiais didáticos elaborados com base em interações naturalísticas, i.e., situações genuínas de fala-eminteração, bem como voltados a atender às necessidades comunicativas imediatas dos imigrantes (MIRANDA; LOPEZ, 2019; PERNA; ANDRIGHETTI, 2019). É essencial que existam livros didáticos ancorados em interações naturalísticas, pois o ensino de PLAc está, segundo Grosso (2010), intrinsecamente relacionado à ação, ou seja, a um saber fazer comunicativo presente no cotidiano dos imigrantes.

Assim, com vistas a aprimorar os materiais didáticos utilizados nos cursos de extensão desenvolvidos em nossa instituição, surgiu o projeto de pesquisa denominado "O português Brasileiro falado na Serra gaúcha como língua de acolhimento para imigrantes", financiado pelos editais IFRS $\mathrm{N}^{\circ}$ 64/2019- Fomento Interno 2020/2021 e IFRS N 15/2020 - Apoio a Projetos Indissociáveis de Pesquisa, Ensino e Extensão nos Campi do IFRS, vinculado ao IFRS - Campus Farroupilha e que conta com a parceria dos campi Farroupilha, Bento Gonçalves e Alvorada do IFRS e da Universidade do Vale dos Sinos $^{4}$. A fim de concretizar esse objetivo, foram realizadas, no primeiro momento, entrevistas com imigrantes instalados no Rio Grande do Sul, visando compreender quais práticas interacionais são necessárias (e mais urgentes) a eles. Dessa maneira, após esse apontamento, nas próximas etapas da pesquisa, serão realizadas gravações em áudio e vídeo de interações naturalísticas nos locais indicados, as quais darão subsídio para o desenvolvimento de materiais didáticos de PLAc.

Dessa forma, o presente artigo tem por objetivo explorar os dados que emergiram das entrevistas realizadas como parte inicial do projeto. Em seguida, apresentamos uma breve revisão teórica sobre o conceito de PLAc; expomos e analisamos os dados referentes às instituições e contextos interacionais elencados como os mais necessários aos imigrantes participantes das entrevistas; discutimos a

\footnotetext{
4 Fica aqui o nosso agradecimento às professoras e aos estudantes voluntários parceiros neste projeto: Isabelle Vogt Biasio, Mateus Gabriel Cabral Bezerra, Profa. Mônica de Souza Chissini e Profa. Lucilene Bender de Sousa do IFRS - Campus Farroupilha; Profa. Carina Fior Postingher Balzan do IFRS - Campus Bento Gonçalves; Profa. Diane Blank Bencke do IFRS Campus Alvorada; Profa. Ana Cristina Ostermann, Profa. Márcia Del Corona e Profa. Graziela Hoerbe Andrighetti da Universidade do Vale do Rio dos Sinos.
} 
problemática da inserção dos imigrantes no mercado formal de trabalho brasileiro, bem como as barreiras que encontram para a sua integração plena à sociedade; e, por fim, tecemos considerações finais, destacando a importância da produção de materiais didáticos de PLAc e os encaminhamentos futuros do projeto.

\section{Português como Língua de Acolhimento no contexto brasileiro}

No contexto das migrações de crise, surge o conceito de Língua de Acolhimento, definido por Grosso (2010, p. 68) como:

\footnotetext{
A língua de acolhimento ultrapassa a noção de língua estrangeira ou de língua segunda. Para o público-adulto, recém-imerso numa realidade linguístico-cultural não vivenciada antes, o uso da língua estará ligado a um diversificado saber, saber fazer, a novas tarefas linguísticocomunicativas que devem ser realizadas na língua-alvo. (GROSSO, 2010, p. 68)
}

O ensino de Português como Língua de Acolhimento (PLAc) é, como mencionado anteriormente, uma das formas mais importantes de acolhimento e integração aos imigrantes que chegam ao Brasil, pois garante 0 atendimento de suas necessidades primordiais, considerando, especificamente, o públicoalvo como pessoas adultas em situações de imigração e/ou refúgio. Sua relevância é evidenciada por Grosso $(2010$, p. 69) ao declarar que "o direito ao ensino/aprendizagem da língua de acolhimento possibilitará o uso dos outros direitos, assim como o conhecimento do cumprimento dos deveres que assistem a qualquer cidadão".

No entanto, atualmente, no Brasil, a oferta de cursos de PLAc é incipiente devido à escassez de políticas públicas nesse sentido. Desse modo, o cenário nacional de ensino de Português para imigrantes é ocupado, majoritariamente, por organizações da sociedade civil (CAMARGO, 2018), tais como ONGs e instituições religiosas, as quais suprem o vácuo deixado pela falta de iniciativas institucionalizadas. Contribuindo para as problemáticas nesse contexto de ensino-aprendizagem, acha-se presente a atuação de profissionais sem qualificação em PLAc (LOPEZ, 2016) e a dificuldade em encontrar materiais didáticos com interações naturalísticas e voltados a atender às necessidades comunicativas imediatas dos imigrantes (MIRANDA; LOPEZ, 2019; PERNA; ANDRIGHETTI, 2019).

O médico cubano Herling Hernández Sterling participou do Programa Mais Médicos para o Brasil e descreveu sua experiência com o estudo da língua portuguesa da seguinte forma: "foi aqui no Brasil que percebi que uma coisa é ouvir um professor que dá aula de português, com um português claro, limpo, devagar, acadêmico; outra coisa completamente diferente é escutar um português popular falado com total naturalidade e facilidade" (STERLING, 2018, p. 195). De modo a colocar os estudantes dos 
cursos de PLAc em contato com as diversas variedades do nosso idioma, é preciso apresentar-lhes interações naturalísticas que sejam representativas da língua falada pelas pessoas que vivem nos locais onde vierem a se instalar, evitando, assim, a disparidade entre o português estudado em sala de aula e o português utilizado em contextos comunicativos cotidianos e institucionais. Só assim poderemos oferecer um ensino de Português Brasileiro como Língua (de fato) de Acolhimento.

No $1^{\circ}$ Encontro Interdisciplinar sobre Ensino de Português para Imigrantes e Refugiados, em 2018, foi destacada a importância de identificar as necessidades dos alunos para "orientar a seleção de quais práticas interacionais seriam mais urgentes aos imigrantes; ou seja, de quais esferas de atividade humana, gêneros do discurso e atividades os imigrantes gostariam e/ou precisariam participar em português (BULLA et al., 2019, p. 117). A pesquisa apresentada neste artigo surgiu exatamente da preocupação em atender à demanda apresentada por Bulla et al. (2019): a pertinência de compreender as necessidades dos imigrantes quanto aos contextos interacionais nos quais se envolvem para viver em nossa sociedade, para, então, trabalharmos com as interações que realmente acontecem nesses contextos nas aulas de PLAc.

\section{Metodologia}

Visando compreender quais práticas interacionais são necessárias (e mais urgentes) aos imigrantes, foram convidados a participar da entrevista 30 imigrantes em situação de crise que residem no Rio Grande do Sul. Boa parte dos entrevistados participaram do Curso de Extensão oferecido pelo IFRS - Campus Bento Gonçalves ou eram conhecidos das membras do grupo de pesquisa. O convite para a participação nas entrevistas e a explicação sobre o funcionamento da pesquisa foram feitos pelas professoras vinculadas ao projeto por meio de contatos telefônicos, respeitando medidas de distanciamento social necessárias ao controle da pandemia de COVID-19.

Depois dessa abordagem inicial, foi enviado aos participantes o Termo de Consentimento Livre e Esclarecido (TCLE) por e-mail, sendo este o documento que explica a finalidade do estudo e garante o anonimato dos entrevistados por meio da utilização de nomes fictícios relacionados a cidades de seus países de origem. $O$ aceite verbal dos participantes também foi solicitado antes do início das entrevistas e registrado na gravação. Do mesmo modo, foi encaminhado a eles o roteiro da entrevista, que, juntamente com o TCLE, foi traduzido para o inglês, espanhol e francês e enviado nesses idiomas para os participantes, conforme a necessidade sinalizada por eles durante a apresentação da pesquisa feita pelas professoras participantes do projeto. Este projeto de pesquisa foi submetido ao Comitê de Ética 
em Pesquisa do IFRS, sendo que os dados foram coletados somente após a sua aprovação, conforme o CAAE: 29648920.7.0000.8024.

Devido ao cenário pandêmico, as 30 entrevistas semiestruturadas foram realizadas e gravadas pela plataforma online Google Meet ao longo do ano de 2020. As entrevistas foram transcritas e analisadas de acordo com a Análise de Conteúdo (BARDIN, 2016). Para tanto, os dados foram categorizados e contabilizados em uma planilha do Google Planilhas.

$\mathrm{Na}$ categorização dos dados, além das respostas das entrevistas relacionadas ao objetivo central do estudo, realizamos alguns destaques referentes aos problemas apontados pelos migrantes, tais como: a inserção dos imigrantes no mercado de trabalho, a interpretação comunitária e alternativas de Políticas de Acolhimento. É importante destacar que as análises realizadas referentes aos temas citados são preliminares e, portanto, devem ser expandidas em estudos específicos. Cada uma dessas problemáticas será discutida em subseções presentes na próxima seção.

\section{Resultados e Discussão}

A seção de Resultados e Discussão está organizada da seguinte maneira: primeiramente, há a uma breve apresentação do perfil dos imigrantes entrevistados, seguida da análise das respostas das perguntas relacionadas aos contextos interacionais necessários ao atendimento das suas demandas. Por fim, há duas subseções com reflexões que não estavam previstas no delineamento inicial da pesquisa, mas que emergiram a partir dos relatos dos imigrantes nas entrevistas e que estão intrinsecamente ligadas ao contexto do ensino e aprendizagem de PLAc. A primeira refere-se à inserção dos imigrantes no mercado formal de trabalho, enquanto a segunda apresenta uma discussão sobre interpretação comunitária e alternativas de Políticas de Acolhimento.

\subsection{Perfil dos entrevistados}

Os resultados das análises das entrevistas foram dispostos em uma planilha do Google Planilhas e contabilizados, conforme os gráficos apresentados a seguir. A primeira parte da entrevista consistiu em perguntas objetivas que nos possibilitaram traçar o perfil dos entrevistados. As Figuras 1, 2 e 3 representam, respectivamente, a quantidade de homens e mulheres que participaram do estudo, divididos por nacionalidade, as suas línguas maternas e o tempo que vivem no Brasil. 


\section{Homens e Mulheres}

Homens Mulheres

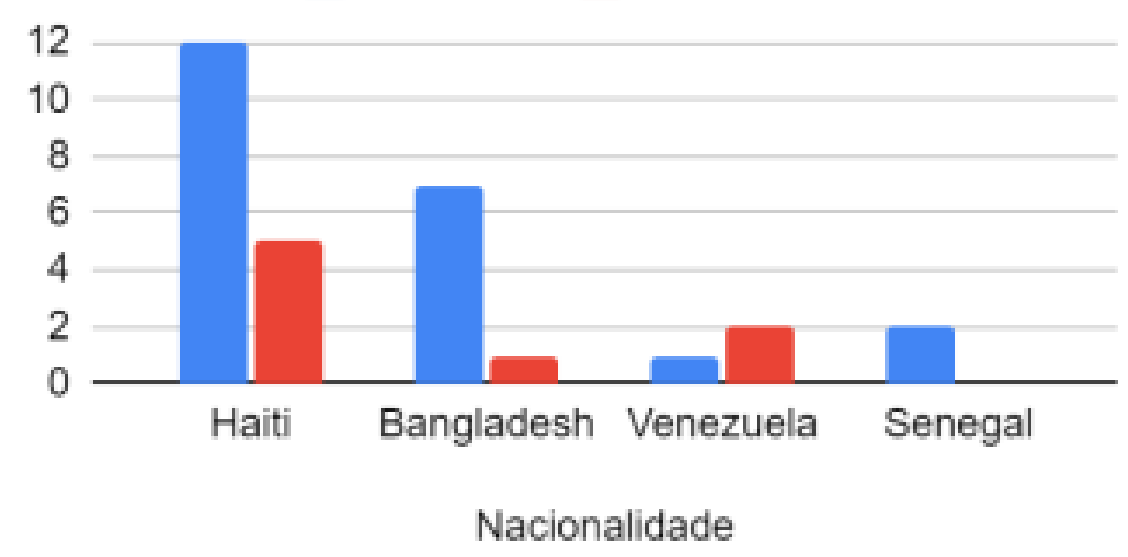

Figura 1. Quantidade de homens e mulheres segundo a nacionalidade dos/as entrevistados/as.

Fonte: Elaborada pelas autoras.

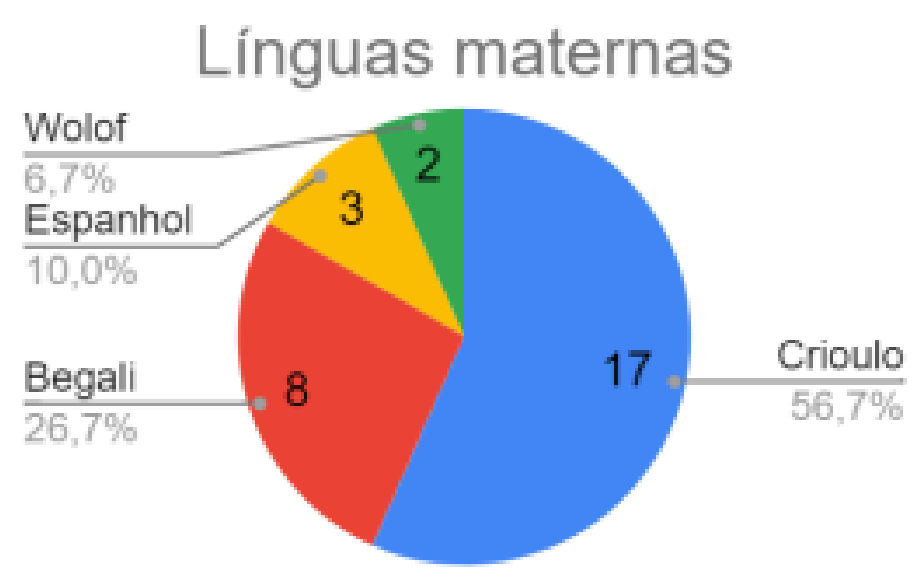

Figura 2. Número de participantes segundo suas línguas maternas.

Fonte: Elaborada pelas autoras. 


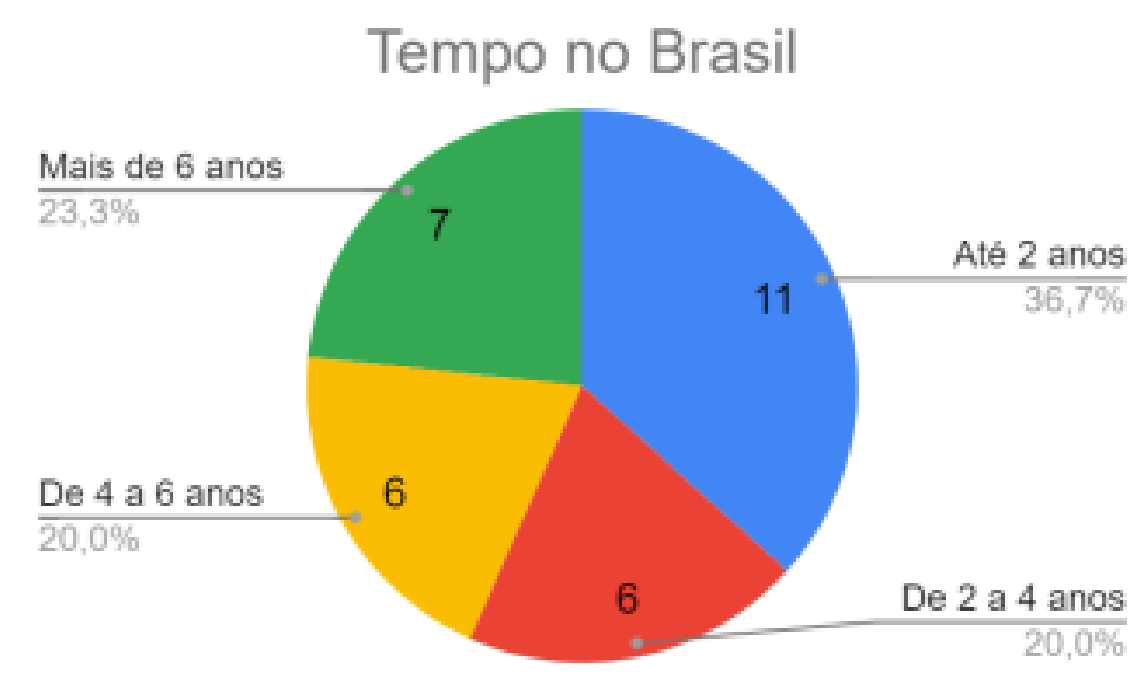

Figura 3. Número de participantes segundo tempo de residência no Brasil.

Fonte: Elaborado pelas autoras.

Conforme ilustrado nas Figuras 1, 2 e 3, a maioria dos entrevistados em nosso estudo foram homens, a nacionalidade mais representativa foi a haitiana, predominando, assim, o crioulo entre as línguas maternas dos participantes, e a maior parte dos imigrantes entrevistados está vivendo no Brasil por até dois anos.

O perfil dos imigrantes entrevistados nesta pesquisa representa uma amostra que se assemelha à maioria dos imigrantes em nosso país. Conforme o relatório do OBMigra (CAVALCANTI et al., 2020), as duas nacionalidades que lideram o número de migrações para o Brasil são a haitiana e a venezuelana. Utilizando o mercado como base para a relação de gêneros, Tonhati e Macedo (2020) argumentam que a imigração em direção ao Brasil é basicamente masculinizada, com $70 \%$ de homens e $30 \%$ de mulheres presentes na área de trabalho formal. 0 tempo em que vivem no Brasil explica-se pelos deslocamentos forçados (geralmente guerras, conflitos, perseguições e desastres naturais) no período de 2010 a 2019.

Visando atender ao objetivo principal da etapa inicial da pesquisa, qual seja, mapear as necessidades dos imigrantes quanto aos contextos interacionais nos quais eles se envolvem, incluímos as seguintes perguntas nas entrevistas: "Quais são as instituições pelas quais você precisa passar para exercer sua cidadania no Brasil?" e "Quais são os locais pelos quais você precisa passar para realizar suas práticas diárias?". Assim, contabilizamos os locais que foram apontados como mais necessários pelos imigrantes, dividindo-os entre contextos institucionais e cotidianos, representados respectivamente pelos gráficos a seguir: 


\section{Instituições relacionadas à cidadania citadas}

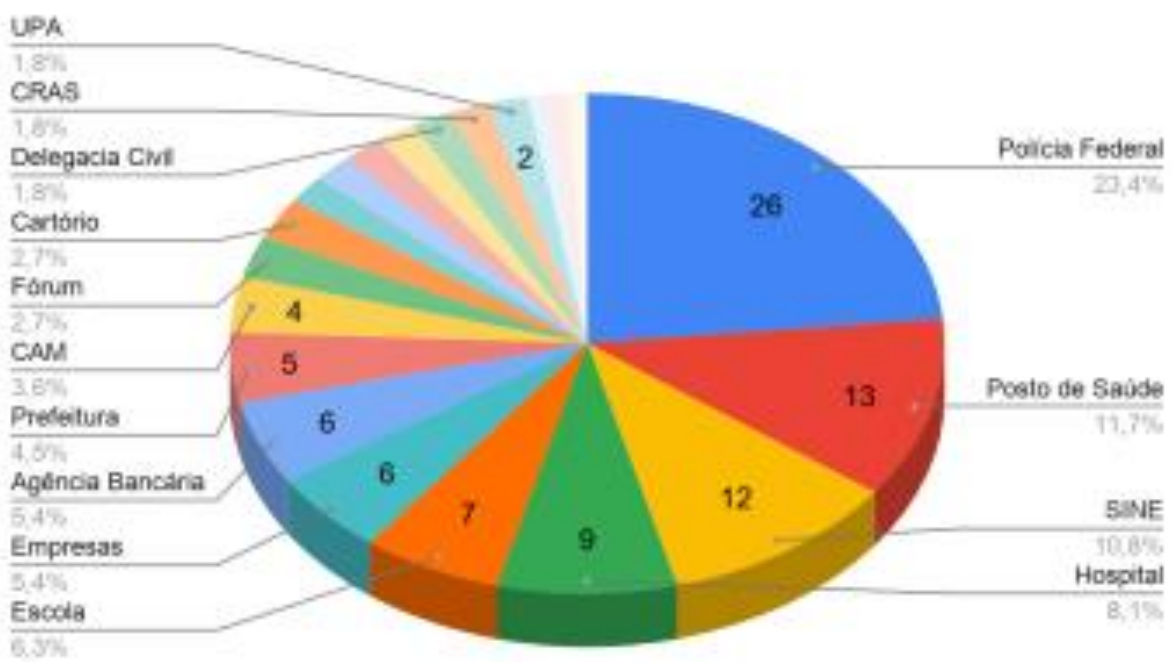

Figura 4. Instituições relacionadas à cidadania segundo número de citações pelos/as entrevistados/as. Fonte: Elaborado pelas autoras.

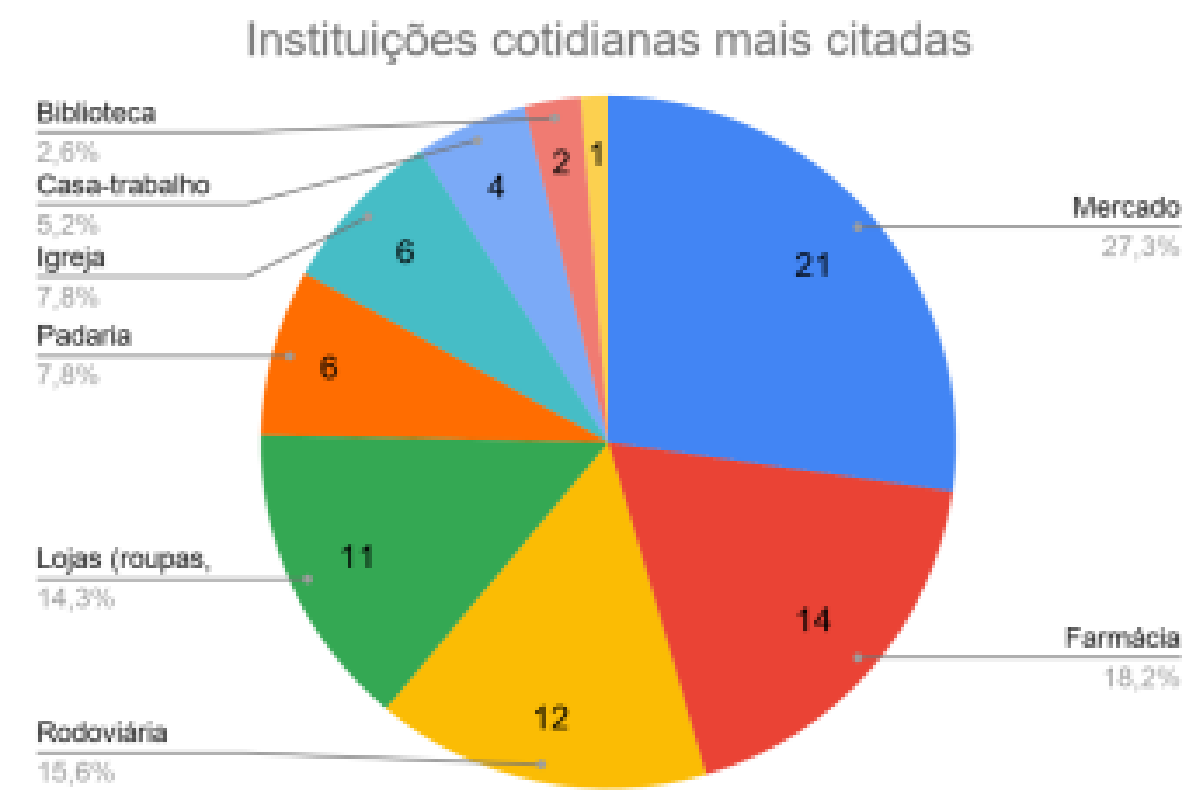

Figura 5. Instituições cotidianas segundo número de citações pelos/as entrevistados/as. Fonte: Elaborado pelas autoras.

Conforme disposto na Figura 4, as cinco instituições relacionadas à cidadania mais citadas nas entrevistas foram Polícia Federal, Sistema Nacional de Emprego (SINE), posto de saúde, hospital e escola. Quando questionados sobre quais instituições cotidianas são as mais necessárias para a realização das suas práticas cotidianas, as mais recorrentes nas falas dos entrevistados foram mercado, 
rodoviária, farmácias e lojas.

Ao analisar os livros de PLAc: "Entre nós: português com refugiados" (ARANTES, 2018), "Língua Portuguesa para Haitianos" (PIMENTEL, 2014), "Passarela: português como língua de acolhimento para fins acadêmicos" (FREITAS, 2020), "Pode Entrar" (FEITOSA et al, 2018), "Portas Abertas" (SÃO PAULO, 2021) e "Vamos juntos" (BIZON, DINIZ e CAMARGO, 2020), percebe-se que há poucos exercícios com interações nos contextos citados como os mais importantes para os imigrantes. Ainda, não há representação de interações nos seguintes contextos: SINE, mercado, rodoviária e farmácia.

O livro "Portas Abertas", por exemplo, apresenta exercícios com interações em lojas e hospitais. No entanto, percebe-se que os diálogos foram criados, devido às marcas da norma padrão que não são costumeiramente utilizadas na fala-em-interação, como as empregadas nestes diálogos retirados do material: "Estou com muita dor de cabeça e no corpo." e "Vou te passar estes remédios." (SÃO PAULO, 2021, p. 119). Diversos estudos citados por Schwindt e Chaves (2019) apontam o apagamento do ' $r$ ' nos verbos no infinitivo no português brasileiro falado. Por exemplo, costumamos dizer "passá" em vez de "passar". Além disso, o verbo "estar" é comumente abreviado na fala: "tô, tá, tava" etc. (PINHEIRO, 2020). Desse modo, uma pesquisa que envolva interações naturalísticas realizadas nos contextos mencionados pelos imigrantes em nossas entrevistas se faz importante para que possamos produzir materiais didáticos que representem genuinamente a língua como ela é utilizada nesses contextos.

4.2 "Tem trabalhos que são especificamente pra brasileiro, que não é pra estrangeiro": inserção de imigrantes no mercado de trabalho

Algumas justificativas e motivos para a dificuldade dos imigrantes no acesso ao mercado de trabalho formal são aludidas nas falas de participantes desta pesquisa. A seguir, apresentamos algumas falas proferidas pelos imigrantes participantes da pesquisa relacionadas à temática do trabalho; para isso, serão utilizados os nomes fictícios atribuídos a eles.

San Tomé, senegalês que vive há seis anos no Brasil, evidencia a importância do trabalho na vida dos imigrantes e no alcance de seus objetivos ao relatar que "[...] mas em cima disso eu tive um sonho, e um objetivo que era estudar, mas esse objetivo, eu não poderia realizar ele sem ter a estabilidade econômica, então precisava trabalhar". Sua fala associa-se às ideias de Sayad (1980 apud DIAS et al., 2020, p. 7), o qual afirma que

[...] se por um lado é verdade que a razão essencial da emigração reside na busca de trabalho e que é também o trabalho que pode, sozinho, justificar a presença do imigrante, por outro este se encontra [...] numa situação excepcionalmente diferente daquela do trabalhador nativo (ou nacional). 
Já Aquin, haitiano que reside há dois anos no Brasil, aponta para as diferenças existentes entre as ocupações dos imigrantes e dos brasileiros no mercado formal de trabalho do país, sendo respaldado pelas informações do Relatório OBMigra 2020 de que a média salarial para imigrantes foi inferior à dos brasileiros entre os anos de 2011 a 2019, bem como de que, no mesmo intervalo de tempo, destacamse, entre essa população, ocupações consideradas de baixa qualificação (CAVALCANTI et al., 2020). Ele declara que "a parte da educação é difícil, né, pra conseguir um reconhecimento de estudo, difícil pra serviço. Todo serviço que tem, tem umas que são bem específico, especificamente pra nós".

Em consonância com sua fala, La Esmeralda, imigrante venezuelana que vive há um ano no Brasil, alude aos empecilhos identificados por ela para a revalidação de seu diploma, outra barreira ao acesso dos imigrantes ao mercado de trabalho formal. Devido a esse obstáculo burocrático, tem trabalhado em áreas diferentes de sua formação inicial. Ela explica que "meu meta traçada aqui é este trabalhar de mi profissão, mas así, é muito difícil pela língua e meu título no vale, no és válido aqui [...]".

Atualmente, no Brasil, o processo de revalidação de diplomas estrangeiros é regulamentado pela Resolução $n^{0} 3$ do Conselho Nacional de Educação (CNE), de 22 de junho de 2016, a qual estabelece, entre outras normas, a documentação necessária para o requerimento da revalidação. Esta, no entanto, pode ser inacessivel aos imigrantes, pois, de acordo com o documento, os candidatos devem apresentar, além de "informações complementares acerca das condições de oferta do curso para subsidiar a avaliação" (CNE, 2016) que podem ser solicitadas pela universidade pública revalidadora,

\footnotetext{
I - cópia do diploma [...];

II - cópia do histórico escolar [...];

III - projeto pedagógico ou organização curricular do curso [...];

IV - nominata e titulação do corpo docente vinculado às disciplinas cursadas pelo(a) requerente, autenticadas pela instituição estrangeira responsável pela diplomação; (CNE, 2016)
}

A Resolução ainda permite que a universidade revalidadora solicite a tradução desses documentos no parágrafo $4^{\circ}$ de seu artigo $7^{\circ}$, o que gera mais um obstáculo aos imigrantes. Além dessas dificuldades, a Portaria do MEC $n^{0} 22$ de 13 de dezembro de 2016, que também trata do assunto, estabelece, no seu artigo 10, outro empecilho a essa população: a taxa cobrada pela instituição revalidadora/reconhecedora de diplomas (BRASIL, 2016).

A suscetibilidade dos imigrantes é mencionada por San Tomé quando este afirma que "às vezes um estrangeiro pode chegar no lugar como um coitado, não tem nada bolso e qualquer vaga que vir ele vai entrar ali". Ainda, segundo ele, "as empresas querem se aproveitar da ignorância de língua pra botar a pessoa em lugar que ninguém queria estar". Portanto, uma vez que essa população se encontra, muitas 
vezes, num contexto de vulnerabilidade social e econômica e de desconhecimento do português, ela é vítima da precarização de seu trabalho.

Abricots, que é haitiano e reside no Brasil há seis anos, relata a discriminação sofrida pelos imigrantes ao se candidatarem para uma vaga de emprego, pois existem empresas que declaram abertamente sua xenofobia ao assumir que não os contratam. Essa questão pode ser observada no seguinte desabafo feito por Abricots: "é, isso dói. E tem vaga, mas eles dizem não é vaga pra estrangeiro, entendeu?". Esse acontecimento relaciona-se à análise de Sayad (1998 apud CAVALCANTI et al., 2019), pois este aponta que, não bastando estarem reduzidos somente à sua força de trabalho, o imigrante vê negada sua capacidade para o trabalho "[...] quando adentra territórios fechados ao conjunto de sua identidade [...]" (SAYAD, 1998 apud CAVALCANTI et al., 2019, p. 187).

Apesar dessa situação, na legislação brasileira, diferentes documentos preveem a ilegalidade da discriminação contra imigrantes no ambiente de trabalho. Relacionando-se ao incidente relatado por Abricots, 0 artigo $1^{\circ}$ da Lei 9.029/95 ressalta que

é proibida a adoção de qualquer prática discriminatória e limitativa para efeito de acesso à relação de trabalho, ou de sua manutenção, por motivo de sexo, origem, raça, cor, estado civil, situação familiar, deficiência, reabilitação profissional, idade, entre outros [...] (BRASIL, 1995).

Além disso, a despeito da discriminação sofrida por esse imigrante, a Constituição Federal de 1988, em seu artigo 5, afirma que "todos são iguais perante a lei, sem distinção de qualquer natureza, garantindo-se aos brasileiros e aos estrangeiros residentes no País a inviolabilidade do direito à vida, à liberdade, à igualdade, à segurança e à propriedade [...]" (BRASIL, 1988).

As problemáticas relacionadas com a inserção dos/as imigrantes no mercado formal de trabalho brasileiro evidenciadas até aqui podem ser solucionadas ou amenizadas com a adoção de medidas apresentadas no Módulo 9 do curso "MigraCidades: aprimorando a governança migratória local". Algumas dessas iniciativas são: auxílio na regularização migratória, apoio a projetos de empreendedorismo, contratação de imigrantes nos serviços públicos (como mediadores linguísticos, por exemplo), ações informativas sobre a legislação trabalhista, oferta de cursos técnicos etc.

4.3 "Ninguém quer integrar nós na sociedade, né?": interpretação comunitária e alternativas de Políticas de Acolhimento

Como citamos anteriormente, o Brasil sofre com a falta de políticas públicas de acolhimento. Embora a Lei 13.445/2017, em tese, garanta direitos igualitários aos imigrantes e refugiados, não 
expande o discurso ao que se trata das diferentes esferas do poder público para assegurar os direitos de cidadania e promover o bem-estar da população migrante (CAMARGO, 2018). Para que haja de fato uma ação de "acolher", é necessário que ambas as partes, governamentais e sociedade civil, trabalhem em conjunto. Como conclui Camargo (2018), é preciso: "[...] oficializar as ações que garantam atendimento digno e necessário aos migrantes de crise, colocando-as como um dever do Estado, sem, contudo, ignorar as microagências da sociedade civil".

Dentre alguns avanços necessários em relação às políticas de acolhimento, encontra-se a interpretação comunitária. Segundo Origuela (2014, p. 226),

A Interpretação Comunitária caracteriza-se por qualquer tipo de interpretação dirigida a um cliente e um prestador de serviços dentro de contexto hospitalar, forense, judiciário e similares. Serve àqueles que vêm de outros países, imigrantes ou os que buscam asilo político como refugiados, a se comunicarem e acessarem os serviços educacionais, judiciários e médicos daquele país em que residem agora, mas não sendo fluentes na língua, necessitam da ajuda de um intérprete.

Ou seja, a interpretação comunitária é essencial para a garantia dos direitos das populações que desconhecem o idioma utilizado nos serviços públicos, sendo essas, além de imigrantes, indígenas e minorias linguísticas já estabelecidas no Brasil. Caso nosso país dispusesse de intérpretes comunitários, situações como a relatada pelo entrevistado senegalês San Tomé seriam evitadas:

Um estrangeiro que está sentindo dor, e não consegue traduzir essa dor, assim se comunicando contigo, explicando eu tenho dor de cabeça, cara, ele tem duas dor. Não é somente dor de cabeça, é dor de não conseguir expressar o sentimento dele.

O Estado brasileiro não possui nenhuma política linguística oficial a respeito dos imigrantes e refugiados em termos de atendimento a essa população em serviços públicos. Entretanto, tramita no senado o Projeto de Lei $n^{\circ} 5182$, de 2020, que, caso aprovado, torna obrigatória a inserção de tradutor e de intérprete comunitário em ambientes institucionais de atendimento ao público para prover assistência linguística a todas as pessoas que não falam português brasileiro. Dessa forma, elas terão garantidos seus direitos civis de acesso a serviços públicos de saúde, justiça, educação, assistência social etc. Além disso, o projeto determina a regulamentação da profissão de tradutor e intérprete comunitário. Alguns municípios já vêm adotando essa prática, como é o caso de Bento Gonçalves, onde o imigrante haitiano Jonel Pierre foi contratado para mediar interações entre imigrantes haitianos que não falam português e profissionais da saúde.

$\mathrm{Na}$ falta de um profissional intérprete, a ação ocorre de forma voluntária, através de amigos ou conhecidos que também são imigrantes. Essa situação foi citada em várias entrevistas, como relata o 
haitiano Ennery, que está no Brasil há 8 anos: "Bom, pra começar foi muito difícil até que tinha que ir com amigos pra conseguir explicar melhor pra mim".

Ao longo da pesquisa, percebemos a problemática em torno da integração de imigrantes, assim como o reconhecimento do imigrante como pessoa. Essa dificuldade é retratada nas seguintes falas do entrevistado haitiano Arcahaie, que reside no Brasil há dois anos: "Bom, dificuldades são muitas. Primeiro, teve gente que não conhece nós como gente"; ele prossegue sua reflexão sobre a falta de integração na sociedade brasileira: "A última coisa pra mim o problema é o problema de integração cultural, religioso, social, política, mas nós somos gente política também, sabe pensar, que tem filosofia, que tem coisas, mas bah é difícil, é difícil".

A partir dessas falas dos imigrantes, é possível perceber que ainda há um longo caminho a percorrer a fim de que a integração de imigrantes seja concretizada e de que o nosso país se torne efetivamente acolhedor. Nesse sentido, Camargo (2018, p. 61), aponta, em consonância com os relatos dos entrevistados, que, atualmente, sob a perspectiva de acolhimento no Brasil,

entre os desafios trazidos pelo novo contexto, encontram-se a implementação da Lei 13.445/2017 [...] e a elaboração de políticas de acolhimento que promovam e viabilizem a (re)territorialização dos migrantes de crise no Brasil por meio do acesso a informações, do trabalho legalizado e do direito ao aprendizado da língua portuguesa, para citar algumas ações. (CAMARGO, 2018, p. 63).

Entende-se que o conhecimento da língua e a disseminação de informações sobre seus direitos contribuem para uma recepção mais acolhedora dos imigrantes. A quebra das barreiras linguísticas é o impedimento mais evidente, porém, ainda que esse problema seja solucionado, se faz necessária a elaboração e implementação de uma política migratória alinhada às questões humanitárias que ultrapasse 0 oferecimento de cursos de português (OLIVEIRA; SILVA, 2017).

\section{Considerações Finais}

O presente artigo pretendeu, a partir da constatação da importância do ensino de PLAc para a inserção de imigrantes na sociedade brasileira, apresentar os dados e as análises produzidas a partir de entrevistas realizadas com imigrantes, as quais fizeram parte do projeto "O Português brasileiro falado na Serra Gaúcha como língua de acolhimento para imigrantes". Considerando as observações acerca da temática no contexto brasileiro, constatamos a existência de demanda pela criação de materiais didáticos que contemplem interações naturalísticas em situações cotidianas vivenciadas pelos imigrantes, considerando as variações da língua portuguesa brasileira falada. 
Os objetivos iniciais do projeto foram alcançados, uma vez que elencaram os contextos institucionais e cotidianos mais necessários de acordo com as demandas dos imigrantes entrevistados, quais sejam, Polícia Federal, SINE, posto de saúde, hospital, escola, mercado, rodoviária, farmácia e lojas. Uma breve análise de alguns livros didáticos de PLAc disponíveis revelou que esses materiais não contêm conversas naturalísticas nesses contextos, o que reforça a necessidade desta pesquisa, pois evidencia que os materiais didáticos não estão preparados para atender às demandas dos imigrantes.

A próxima etapa do projeto deverá ser a coleta de interações naturalísticas nos locais indicados, por meio de gravações em áudio e vídeo. Essa etapa, no entanto, poderá ser realizada somente quando as condições sanitárias relacionadas à pandemia de COVID-19 permitirem. Após a coleta, as gravações serão transcritas seguindo a metodologia de Análise da Conversa e utilizadas como referencial para a elaboração de materiais de PLAc adequados para os imigrantes, melhorando, assim, seu aprendizado e, consequentemente, sua comunicação na sociedade.

Destaca-se que, para além dos objetivos iniciais traçados, as falas dos entrevistados geraram desdobramentos do projeto referentes à temática do trabalho, bem como interpretação comunitária e políticas de acolhimento. As discussões realizadas acerca dessas problemáticas possibilitaram a compreensão de algumas dimensões envolvidas na inserção dos imigrantes no mercado de trabalho formal do Brasil e nas alternativas relacionadas às políticas de acolhimento. As falas dos imigrantes possibilitaram a compreensão de que a existência de políticas públicas de acolhimento deve transcender as políticas linguísticas, tal qual defendem Oliveira e Silva (2017).

\section{Referências}

ARANTES, P. C. C. (coord). Entre nós: português com refugiados. Rio de Janeiro-RJ: Cartolina, 2018. Disponivel em: https://d96e87dd-dfcf-4eb8-8af866f7b09f340f.filesusr.com/ugd/48e29d_e1c2f7f5e7934c8b9121e1c25f7b5048.pdf. Acesso em: 19 mar. 2021.

BAENINGER, R; PERES, R. Migração de crise: a migração haitiana para o Brasil. Revista Brasileira de Estudos de População, Belo Horizonte, v. 34, n. 1, p. 119-143, jan./abr. 2017. Disponível em: https://www.scielo.br///rbepop/a/MzJ5nmHG5RfN87c387kkH7g/?format=pdf\&lang=pt. Acesso em: 31 ago. 2021. http://dx.doi.org/10.20947/S0102-3098a0017

BALZAN, C. F. P; KANITZ, A. Língua Portuguesa para imigrantes e refugiados: relato de uma experiência no IFRS - Campus Bento Gonçalves. LínguaTec, Bento Gonçalves, v. 5, n. 1, p. 273-284, jun. 2020. https://doi.org/10.35819/linguatec.v5.n1.4012 
BARALDI, C. B. F.; STEFFENS, I. da S.; ALBUQUERQUE, M. C. de. Curso MigraCidades: aprimorando a governança migratória local: módulo 9 - Acesso ao mercado do trabalho. 2020. Disponível em: https://repositorio.enap.gov.br/handle/1/5092. Acesso em: 19 mar. 2021.

BARDIN, L. Análise de conteúdo. Lisboa: Edições 70, 2016.

BIZON, A. C. C.; DINIZ, L. R. A; CAMARGO, H. R. E. de. Coleção Vamos Junto(as)! Curso de Português como Língua de Acolhimento: Trabalhando e estudando (Livro do(a) estudante). Campinas: Nepo/Unicamp, 2020.2 Disponível em: https://www.nepo.unicamp.br/publicacoes/livros/vamosjuntos/trabalhando_estudando.pdf. Acesso em: 19 mar. 2021.

BRASIL. Lei $n^{0}$ 13.445, de 24 de maio de 2017. Lei de Migração. Brasília, DF: Presidência da República, 24 mai. 2017. Disponível em: http://www.planalto.gov.br/ccivil_03/_ato2015-2018/2017/lei/l13445.htm. Acesso em: 25 ago. 2021.

BRASIL. [Constituição (1988)]. Constituição da República Federativa do Brasil. Brasília, DF: Presidência da República, 5 out. $1988 . \quad$ Disponível em: http://www.planalto.gov.br/ccivil_03/constituicao/constituicao.htm. Acesso em: 17 mar. 2021.

BRASIL. Lein ${ }^{\circ}$ 9.029, de 13 de abril de 1995. Proíbe a exigência de atestados de gravidez e esterilização, e outras práticas discriminatórias, para efeitos admissionais ou de permanência da relação jurídica de trabalho, e dá outras providências. Brasília, DF: Presidência da República, abr. 1995. Disponível em: http://www.planalto.gov.br/ccivil_03/leis/l9029.htm. Acesso em: 17 mar. 2021.

BRASIL. Ministério da Educação. Portaria Normativa $n^{0} 22$, de 13 de dezembro de 2016. [Dispõe sobre normas e procedimentos gerais de tramitação de processos de solicitação de revalidação de diplomas de graduação estrangeiros e ao reconhecimento de diplomas de pós-graduação stricto sensu (mestrado e doutorado), expedidos por estabelecimentos estrangeiros de ensino superior. Diário Oficial da União: seção 1, Brasília, DF, 14 dez. 2016. Disponível em: https://www.in.gov.br/materia/lasset_publisher/Kujrw0TZC2Mb/content/id/22190733/do1-2016-12-14-portaria-normativa-n-22-de-13de-dezembro-de-2016-

22190702\#: :text=Disp \%C3\%B5e\%20sobre\%20normas\%20e\%20procedimentos,por\%20estabelecime ntosestrangeiros\%20de\%20ensino\%20superior. Acesso em: 18 mar. 2021.

BRASIL. Senado Federal. Projeto de lei $n{ }^{\circ} 5182 / 2020$ de 17 de nov. 2020. Torna obrigatória a inserção de tradutor e de intérprete comunitário em ambientes institucionais de atendimento ao público para prover assistência linguística a todas as pessoas que não falam português brasileiro. Determina a regulamentação da profissão de tradutor e intérprete comunitário. Disponível em: https://www25.senado.leg.br/web/atividade/materias/-/materia/145443. Acesso em: 25 ago. 2021.

BULLA, G. da S. et al. Português para imigrantes e refugiados na UFRGS: ações de política linguística e educacional. In: FERREIRA, Luciane Corrêa et al. (Org.). Língua de Acolhimento: experiências no Brasil e no mundo. Belo Horizonte: Mosaico Produção Editorial, 2019. p. 113-120. Disponível em: http://www.letras.ufmg.br/padrao_cms/documentos/profs/luciane/capa_linguadeacolhimentoEBOOK\%2 ODEFINITIVO.pdf. Acesso em: 26 ago. 2021. 
CAMARGO, H. R. E. Portas Entreabertas do Brasil: narrativas de migrantes de crise sobre políticas públicas de acolhimento. Revista $X$, Curitiba, v. 13, n. 1, p. 57-86, 2018. http://dx.doi.org/10.5380/rvx.v13i1.60325

CAVALCANTI, L; OLIVEIRA, T.; MACEDO, M. Imigração e Refúgio no Brasil. Relatório Anual 2020. Série Migrações. Observatório das Migrações Internacionais; Ministério da Justiça e Segurança Pública/ Conselho Nacional de Imigração e Coordenação Geral de Imigração Laboral. Brasília, DF: OBMigra, 2020.

CAVALCANTI, L. et al. Imigração haitiana em Curitiba e crise econômica: o emprego estratégico das redes migratórias e os capitais de mobilidade em contexto de crise. Monções, Dourados, v.8. n.16, p. 165-195, 2019. http://dx.doi.org/10.30612/rmufgd.v8i16.11048

CONSELHO NACIONAL DE EDUCAÇÃO. Dispõe sobre normas referentes à revalidação de diplomas de cursos de graduação e ao reconhecimento de diplomas de pós-graduação stricto sensu (mestrado e doutorado), expedidos por estabelecimentos estrangeiros de ensino superior. Resolução CNE/CES no 3 , de 22 de junho de 2016. Disponível em: http://portal.mec.gov.br/index.php?option=com_docman\&view=download\&alias=44661-rces003-16pdf\&category_slug=junho-2016-pdf\&ltemid=30192. Acesso em: 18 mar. 2021.

DIAS, G.; et al. A contemporaneidade do pensamento de Abdelmalek Sayad. São Paulo: EDUC, 2020. Disponível em: https://www.pucsp.br/educ/downloads/Abdelmalek_Sayad.pdf. Acesso em: 07 set. 2021.

FEITOSA, J.; et al. Pode entrar: Português do Brasil para refugiados e refugiados. 1.ed. São Paulo - SP. Disponível em: https://www.caritassp.org.br/wp-content/uploads/2019/06/PODE-ENTRAR.pdf. Acesso em: 18 mar. 2021.

FREITAS, Al. de; et al. Passarela: português como língua de acolhimento para fins acadêmicos. Curitiba: Editora Peregrina, 2020. Disponivel em: https://www.acnur.org/portugues/wpcontent/uploads/2020/08/Passarela_Portugues-como-lingua-de-acolhimento-para-fins-academicos.pdf. Acesso em: 19 mar. 2021.

GABRIEL, M.; ALBUQUERQUE, J. I. Al. de; BORDINI, M. I. S. Conjunturas politicas em contexto de migração e refúgio: um olhar glotopolítico. ReVEL. v. 18, n. 35, p. 242-268, 2020. Disponível em: http://www.revel.inf.br/files/c37fa258c710e38a3c8b5e9ff00959cb.pdf. Acesso em: 31 ago. 2021.

GROSSO, M. J. dos R. Língua de acolhimento, língua de integração. Horizontes de Linguística Aplicada, Brasília, v. 9, n. 2, p. 61-77, 2010. https://doi.org/10.26512/rhla.v9i2.886

IBGE - INSTITUTO BRASILEIRO DE GEOGRAFIA E ESTATÍSTICA - Coordenação de População e Indicadores Sociais. Instrumentos de gestão migratória. In: __. Perfil dos municípios brasileiros: 2018. Rio de Janeiro: IBGE, 2019. p. 96-111. Disponível em: https://biblioteca.ibge.gov.br/visualizacao/livros/liv101668.pdf. Acesso em: 26 ago. 2021.

LOPEZ, A. P. A. Subsídios para o planejamento de cursos de português como língua de acolhimento para imigrantes deslocados forçados no Brasil. 2016. 260 f. Dissertação (Mestrado em Linguística Aplicada) - Faculdade de Letras, Universidade Federal de Minas Gerais, Belo Horizonte, 2016. 
Disponivel

em:

https://repositorio.ufmg.br/bitstream/1843/RMSAAJTNHQ/1/disserta_o_poslin_ana_lopez_2016.pdf. Acesso em: 31 ago. 2021.

MIRANDA, Y. C. C.; LOPEZ, A. P. A. Considerações sobre a formação de professores no contexto de ensino de Português como Língua de Acolhimento. In: FERREIRA, Luciane Corrêa et al. (org.). Língua de Acolhimento: experiências no Brasil e no mundo. Belo Horizonte: Mosaico Produção Editorial, 2019. p. 17-39.

Disponível

em: http://www.letras.ufmg.br/padrao_cms/documentos/profs/luciane/capa_linguadeacolhimentoEBOOK\%2 ODEFINITIVO.pdf. Acesso em: 31 ago. 2021.

OLIVEIRA, G. M.; SILVA, J. I. Quando barreiras linguísticas geram violação de direitos humanos: que políticas linguísticas o Estado brasileiro tem adotado para garantir o acesso dos imigrantes a serviços públicos básicos? Gragoatá, v. 22, n. 42, p. 131-153, 2017. https://doi.org/10.22409/gragoata.v22i42.33466

ORIGUELA, D. A. Interpretação comunitária, direitos humanos e assistência social proposta de política pública no contexto brasileiro. TradTerm, São Paulo, v. 23, p. 225-240, 2014. https://doi.org/10.11606/issn.2317-9511.tradterm.2014.85578

PERNA, C. B. L.; ANDRIGHETTI, G. H. As escolhas envolvidas no ensino de PLAc: o que nossas aulas têm a dizer? In: FERREIRA, Luciane Corrêa et al. (org.). Língua de Acolhimento: experiências no Brasil e no mundo. Belo Horizonte: Mosaico Produção Editorial, 2019. p. 141-170. Disponível em: http://www.letras.ufmg.br/padrao_cms/documentos/profs/luciane/capa_linguadeacolhimentoEBOOK\%2 ODEFINITIVO.pdf. Acesso em: 31 ago. 2021.

PIMENTEL, M. L. (coord.); COTINGUIBA, G. C; NOVAES, M. de L. Língua portuguesa para haitianos. 1. ed. Florianópolis: SESI/SC, 2014. Disponível em:

https://www.ufrgs.br/gaire/wp-content/uploads/2016/11/caderno-estudante-HAITIANOS.pdf. Acesso em: 18 mar. 2021.

PINHEIRO, F. P. Variação e gramaticalização: um estudo sobre a redução fonética do item estar. Revista de Estudos da Linguagem, Belo Horizonte, v. 28, n. 3, p. 1131-1159, 2020. Disponível em: http://www.periodicos.letras.ufmg.br/index.php/relin/article/view/15682/pdf. Acesso em: 31 ago. 2021.http://dx.doi.org/10.17851/2237-2083.28.3.1131-1159

STERLING, H. H. De uma ilha distante ao coração da Amazônia: caminhos de um cubano atravessados pelo português. Revista $X$, Curitiba, v. 13, n. 1, p. 192-198, 2018. http://dx.doi.org/10.5380/rvx.v13i1.60861

SÃO PAULO. Secretaria Municipal de Educação. Coordenadoria Pedagógica. Portas Abertas: Português para imigrantes: caderno básico. São Paulo: SME/COPED, 2021. Disponível em: https://www.prefeitura.sp.gov.br/cidade/secretarias/upload/direitos_humanos/caderno\%20basico.pdf. Acesso em: 05 set. 2021.

SCHWINDT, L. C; CHAVES, R. G. Convergência de processos no apagamento de /r/ em português e espanhol. Linguística, Montevideo, v. 35, n. 1, 2019. http://dx.doi.org/10.5935/2079-312x.20190007 
TONHATI, T.; MACEDO, M. Imigração de mulheres no Brasil: movimentações, registros e inserção no mercado de trabalho formal (2010-2019). PÉRIPLOS, Brasília, v. 4, n. 2, p. 125-155, 2020. Disponível em: https://periodicos.unb.br/index.php/obmigra_periplos/article/view/35905/28629. Acesso em: 31 ago. 2021.

Data de submissão: 10/09/2021. Data de aprovação: 24/10/2021. 